\title{
Impact of instantaneous sea ice removal in a coupled general circulation model
}

\author{
D. Schröder ${ }^{1,2}$ and W. M. Connolley ${ }^{1}$ \\ Received 3 April 2007; revised 9 May 2007; accepted 7 June 2007; published 19 July 2007.
}

[1] The impact of extreme sea ice initial conditions on modelled climate is analysed for a fully coupled atmosphere ocean sea ice general circulation model, the Hadley Centre climate model HadCM3. A control run is chosen as reference experiment with greenhouse gas concentration fixed at preindustrial conditions. Sensitivity experiments show an almost complete recovery from total removal or strong increase of sea ice after four years. Thus, uncertainties in initial sea ice conditions seem to be unimportant for climate modelling on decadal or longer time scales. When the initial conditions of the ocean mixed layer were adjusted to ice-free conditions, a few substantial differences remained for more than 15 model years. But these differences are clearly smaller than the uncertainty of the HadCM3 run and all the other 19 IPCC fourth assessment report climate model preindustrial runs. It is an important task to improve climate models in simulating the past sea ice variability to enable them to make reliable projections for the 21 st century. Citation: Schröder, D., and W. M. Connolley (2007), Impact of instantaneous sea ice removal in a coupled general circulation model, Geophys. Res. Lett., 34, L14502, doi:10.1029/ 2007GL030253.

\section{Introduction}

[2] Sea ice plays an important role in the heat exchange between the ocean and atmosphere at high latitudes and interacts with the broader climate system due to its impact on ocean stratification [Curry and Webster, 1999], via the ice albedo feedback [Ebert and Curry, 1993] and the insulation effect [Zhang et al., 1995]. Observations reveal a decrease in sea ice cover over the last 30 years in the Arctic [Stroeve et al., 2005], but no significant trend in the Antarctic [Vinnikov et al., 2006]. In the 21st century, projections from coupled climate models show a large range of responses in both hemispheres varying from a small to a dramatic decrease of sea ice extent [Zhang and Walsh, 2006; Arzel et al., 2006]. Two IPCC fourth assessment report climate models (MPI ECHAM5 and NCAR CCSM3.0) even become year-round sea-ice-free in the 22nd century ( $1 \% /$ year of $\mathrm{CO}_{2}$ increase to quadrupling - SRES A2) [Winton, 2006]. What will happen when sea ice disappears in the future? Will global warming be amplified? Serreze and Francis [2006] expect a substantial increase in Arctic Ocean surface air temperature at the time summer sea ice

\footnotetext{
${ }^{1}$ British Antarctic Survey, Natural Environment Research Council, Cambridge, UK.

${ }^{2}$ Now at University of Trier, Department of Environmental Meteorology, Faculty of Geoscience, Trier, Germany.

Copyright 2007 by the American Geophysical Union. 0094-8276/07/2007GL030253
}

shrinks below a threshold value. Winton [2006] analysed these two runs which became sea-ice-free and found only small nonlinearity with respect to temperature change by the time sea ice disappears totally. Is sea ice only a climate indicator or does it play an active role in climate change?

[3] It is known that ocean initial conditions are critical for climate forecasting [e.g., Rosati et al., 1997] and anomalous ocean conditions have a potential value for at least seasonal forecasting [e.g., Iwi et al., 2006]. Less is known about the effect of initial ice conditions on climate predictability. Wu et al. [1996] removed all the Antarctic sea ice in a coupled atmosphere sea ice model and detected a decrease in sea level pressure during the first few months and a total recovery of ice in the following winter, but they didn't use a full ocean model. In our study the initial sea ice is removed in a fully coupled climate model (including an ocean model) enabling all interaction processes to be taken into account.

\section{HadCM3 Model With EVP Rheology}

[4] The HadCM3 climate model is the Hadley Centre coupled ocean atmosphere sea ice model with 19 levels in the atmosphere and 20 levels in the ocean [Gordon et al., 2000]. An Elastic Viscous Plastic (EVP) sea ice dynamics scheme [Hunke and Dukowicz, 1997] was implemented by Connolley et al. [2006]. The overall sea ice simulation is generally better and more physically based than in HadCM3 [Connolley et al., 2006]. Nevertheless, considerable discrepancies exist between simulated sea ice climate and observations (see Figure 1 for comparison of annual cycle). A major problem is the underestimation of summer sea ice in both hemispheres. The EVP scheme is much the same as the one used in HadGEM1 (Hadley Centre Global Environment Model version 1 [Johns et al., 2006]), the successor to $\mathrm{HadCM} 3$, but the sea ice thermodynamics are different. For this study the HadCM3 version is chosen because more work has been done on its representation of sea ice and sea ice validation [Slingo et al., 2003; Turner et al., 2001, 2006] and also for reasons of computational efficiency. A 20 -year run is used as the reference run (called "Ctrl" in the following) beginning from a standard HadCM3 state taken from the control run, which has greenhouse gas forcing appropriate to pre-industrial levels. Thus, these 20 years are stable with respect to atmospheric and sea ice parameters. The Atlantic Meridional Overturning Circulation does have a small positive trend in the Ctrl run which could cause problems for analysing decadal effects (not carried out in our study).

\section{Sensitivity Experiments: Removal of Sea Ice}

[5] Four sensitivity experiments were performed in which all the initial sea ice was removed on December 1st (starting 

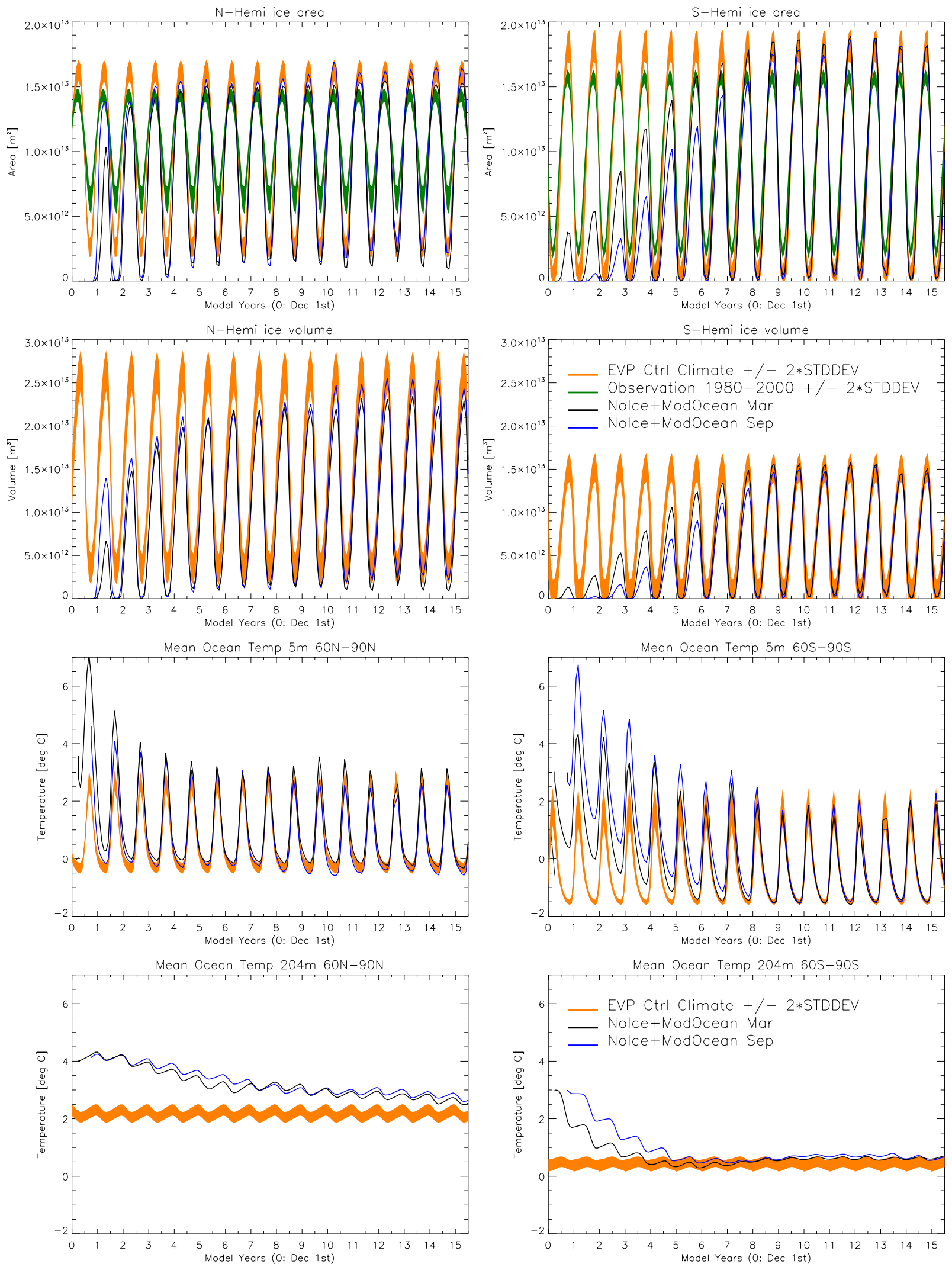

Figure 1. Sensitivity experiments without sea ice and modified ocean temperature: time series of ice area $\left(\mathrm{m}^{2}\right)$, ice volume $\left(\mathrm{m}^{3}\right)$, and area mean $\left(60^{\circ} \mathrm{N}\right.$ to $90^{\circ} \mathrm{N}$ and $60^{\circ} \mathrm{S}$ to $\left.90^{\circ} \mathrm{S}\right)$ ocean temperature at a depth of $5 \mathrm{~m}$ and $204 \mathrm{~m}$. The orange area represents the climate of the Ctrl run \pm twice the standard deviation. The green area represents the observed mean ice area for the period 1980 to 2000 [Comiso, 2003]. 

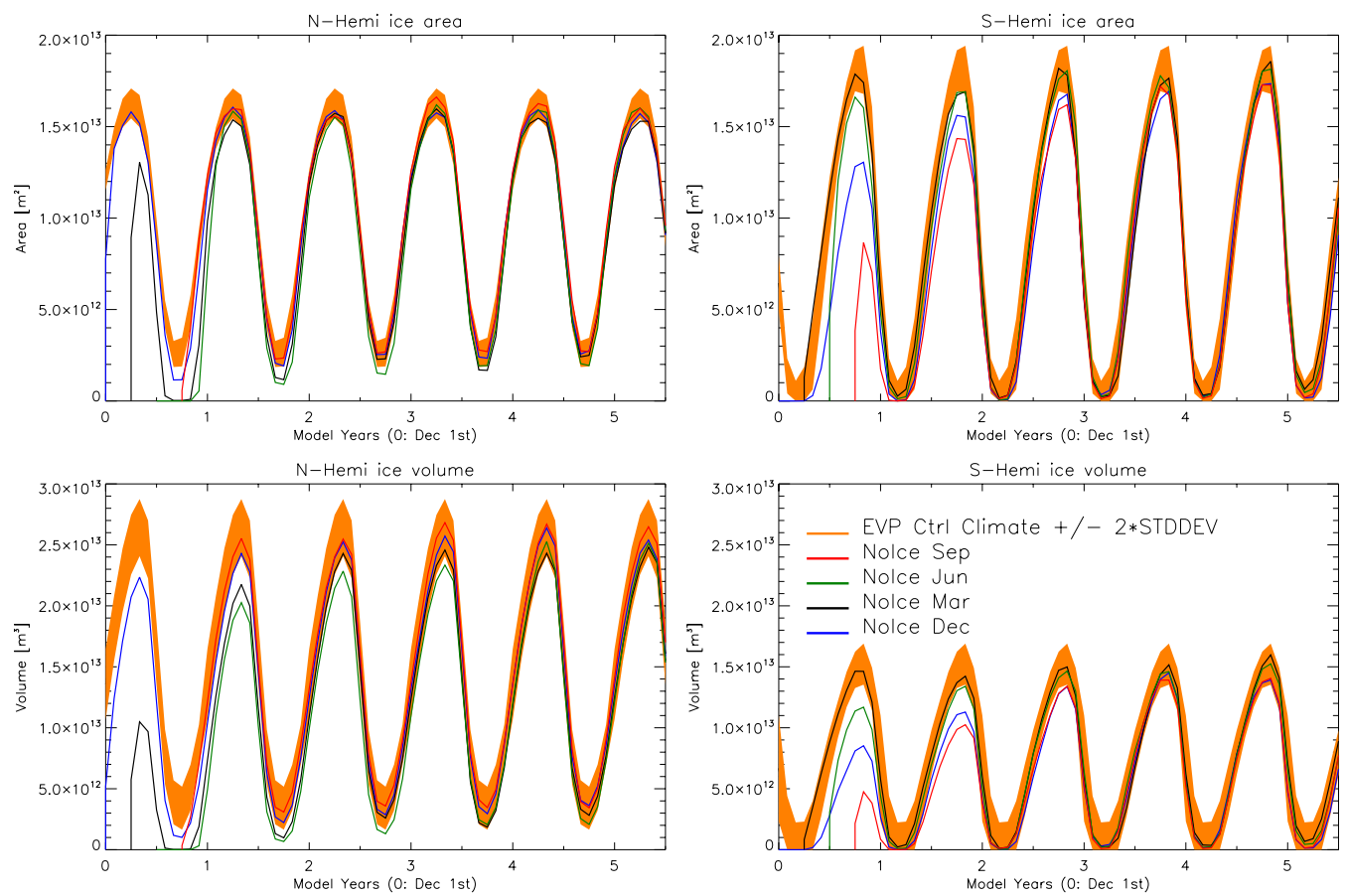

Figure 2. Sensitivity experiments without initial sea ice: time series of ice area $\left(\mathrm{m}^{2}\right)$ and ice volume $\left(\mathrm{m}^{3}\right)$. The orange area represents the climate of the Ctrl run \pm twice the standard deviation.

time of Ctrl run), March 1st, June 1st and September 1st, respectively. Figure 2 compares ice area and ice volume of the sensitivity runs to the climate of the Ctrl run for both hemispheres. Starting without sea ice in December (blue line) the "normal" sea ice area recovers in only one month in the Arctic. How can an ice area of nearly $1.5 \times 10^{13} \mathrm{~m}^{2}$ build up in such a short period? The crucial factor is the temperature of the ocean mixed-layer which has not been modified and is close to freezing point during winter. Thus, the heat flux from the mixed-layer ocean to the surface only amounts to $\sim 20 \mathrm{Wm}^{-2}$ and consequently a loss of energy due to atmospheric cooling of a bit more than that is sufficient to freeze the whole surface of the Arctic Ocean almost instantaneously. In fact, the area mean December freezing rate amounts to $\sim 60 \mathrm{~cm} /$ month (thus the net energy loss is $Q=\rho_{i} \cdot L_{i} \cdot \frac{\partial h}{\partial t} \approx 60 \mathrm{Wm}^{-2}$ with $\rho_{i}=910 \mathrm{~kg}$ $\mathrm{m}^{-3}$ and $\left.L_{i}=0.33 \cdot 10^{6} \mathrm{~J} \mathrm{~kg}^{-1}\right)$ in the Ctrl run and is twice as high as this in the first month after removal of sea ice. Afterwards, the ice layer is already thick enough to insulate the warm ocean from the cold air as effectively as in the Ctrl run and the freezing rate consequently decreases. The same holds for Antarctica if all the sea ice is removed in June (green line). A longer-lasting impact is achieved by removing the sea ice in summer. This is because no sea ice can build up during summer, and if no sea ice is present the reduced surface albedo causes an increase in ocean temperature (up to $2.5 \mathrm{~K}$ for the area mean in the Arctic and $1 \mathrm{~K}$ in the Antarctic at a depth of $5 \mathrm{~m}$ ) which delays freezing in the next autumn. The impact of seasonality found when sea ice is removed differs from the study of Wu et al. [1996], in which the strongest effect occurs when the sea ice is removed at its maximum coverage (late winter). The disagreement can be explained by the different models. Wu et al. [1996] have applied an atmospheric sea ice model with a one layer ocean beneath sea ice. Thus, they couldn't resolve the heating process of the mixed-layer ocean, which is the dominating effect in our study.
[6] Analysing horizontal distributions of sea ice, atmospheric and ocean parameters (not shown) there are differences clearly larger than the variability of Ctrl during the first years. Removal of sea ice leads to an increase of ocean, surface and air temperature, an increase in salinity due to a lack of freshwater from melting ice [Meredith and King, 2005] and a decrease in sea level pressure in the Arctic and Antarctica (in agreement with Wu et al. [1996]), but the impact does not last for more than a few years. After four years almost no signals can be found which are stronger than noise (see Figure 2). With the exception of a longer-lasting positive anomaly of salinity in some regions the model climate did completely recover from the removal of sea ice, because the ocean mixed layer is effectively preconditioned to a state to form sea ice. Even when the sea ice is removed in summer this state is only marginally warmed.

[7] To complement the experiments with decreased sea ice, we consider what will happen if sea ice area and volume are increased. Therefore further experiments are performed in which all parts of the ocean with a surface temperature of less than (1) $5^{\circ} \mathrm{C}$ and (2) $15^{\circ} \mathrm{C}$ are artificially covered by a $2 \mathrm{~m}$ sea ice layer. The recovery back to the original state is as fast as in the experiments with removed sea ice (not shown). The sea ice almost immediately melts in the warm ocean and only reduces the ocean temperature and salinity by up to $3 \mathrm{~K}$ and $1 \mathrm{psu}$ in the uppermost layer. The heat equivalence of $2 \mathrm{~m}$ of ice amounts to an increase of a $200 \mathrm{~m}$ thick ocean mixed layer by $0.75 \mathrm{~K}$.

\section{Sensitivity Experiments: Modified Mixed-Layer Ocean}

[8] The preceding experiments were somewhat unrealistic because although the ice was removed, the ocean was still in a state compatible with ice cover. Hence, in the 
following experiments the ocean temperature will be modified to examine an ice-free situation in the real world where an ice anomaly is connected with an ocean heat anomaly. Where and how should the ocean temperature be modified to simulate a realistic ice-free situation? To answer this question the annual cycle of the ocean is analysed in the transitional zone with seasonal sea ice (not shown). The uppermost $200 \mathrm{~m}$ of the polar oceans are affected by seasonal changes in the HadCM3 run. A maximum ocean temperature of about $3^{\circ} \mathrm{C}$ is reached in areas which are seasonally covered by sea ice. Based on these findings two further sensitivity experiments are performed in which the initial global sea ice is removed and the ocean temperature of the uppermost $200 \mathrm{~m}$ (10 model levels) is artificially increased to a minimum value of $3^{\circ} \mathrm{C}$ on March 1 st and September 1st, respectively. The initial salinity and ocean circulation remain the same as in the Ctrl run.

[9] The results show strong differences between the two hemispheres (Figure 1). In the Arctic, the winter ice area has almost completely reformed after three years - although the ice volume recovers more slowly; and the difference of the areal mean ocean temperature at a depth of $5 \mathrm{~m}$ between sensitivity and $\mathrm{Ctrl}$ run reduces from $4 \mathrm{~K}$ during the first summer (March experiment) to less than $1 \mathrm{~K}$ during the fourth summer. The fast recovery of ice and the fast warming of the uppermost ocean is enabled by the stable stratification of the Arctic Ocean and, thus, the weak vertical exchange. The ocean temperature at a depth of $204 \mathrm{~m}$ increases very slowly and is still higher than in the Ctrl run after 15 years. The Antarctic sea ice recovers more slowly than the Arctic ice because the Antarctic Ocean is less stably stratified. Thus, ocean temperature at all 10 levels and sea ice recover nearly simultaneously after 7 years. There is no clear signal of change in the Atlantic Meridional Overturning Circulation in the first 15 years after sea ice removal. The time scale of the recovery seems to be too short for the development of such large scale interaction processes.

[10] Increasing the ocean temperature in addition to the sea ice removal has a stronger and longer lasting impact in the polar regions and a few substantial differences even exist after 15 years. In some areas these differences are larger than the model interannual variability, but clearly smaller than the differences between modelled and observed ice extent. Figure 1 shows that the simulated summer sea ice area in the Ctrl run is less than $50 \%$ of the observed in both hemispheres. Taking into account that the Ctrl run represents the pre-industrial climate and not the last 20 years of the 20th century the discrepancy would even be a bit larger.

[11] The lack of seasonal summer sea ice in the Ctrl run may be a factor in reducing the memory of the system. To examine this memory, we did a composite analyses of the 400-year HadCM3 Ctrl run comparing the 5 years of minimum as well as maximum sea ice area against the model climate at leads and lags of up to 2 years. The results reveal (not shown) that the annual mean Antarctic sea ice area does not depend on the previous year and that the "memory" only amounts to one year in the Arctic.

\section{Conclusions}

[12] Sensitivity experiments with a fully coupled general circulation model show a complete recovery from a total removal or strong increase of sea ice after four years. These are extreme anomalies and more realistic perturbations would show even faster recovery. Thus, errors in initial sea ice conditions seem to be unimportant for climate modelling on decadal or longer timescales. Furthermore, sea ice anomalies seem to be of low value for annual or decadal forecasting. Though several studies show connections between sea ice anomalies and midlatitude as well as tropical conditions [e.g., Ivchenko et al., 2006] the short persistence of sea ice anomalies found in the 400-year HadCM3 Ctrl run indicates that sea ice is unlikely to be the driving factor.

[13] The impact is stronger when ocean temperature is adjusted to ice-free conditions, but even then the differences appearing between the sensitivity and Ctrl runs are clearly smaller after a few years than the differences between modelled and observed sea ice area. This is not solely a problem of HadCM3, but all the 20 IPCC fourth assessment report climate models show deficiencies in simulating the past sea ice climate and seasonal variability (see Parkinson et al. [2006] for analyses of 11 models). Model improvement seems to be important to reduce the wide range of sea ice change forecasts for the 21 st century [Arzel et al., 2006; Zhang and Walsh, 2006] and to increase the confidence in model results for future changes.

[14] Acknowledgments. David Schröder was supported by the NERC GCEP project.

\section{References}

Arzel, O., T. Fichefet, and H. Goosse (2006), Sea ice evolution over the 20th and 21 st centuries as simulated by current AOGCMs, Ocean Modell., 12, $401-415$.

Comiso, J. (2003), Bootstrap sea ice concentrations for Nimbus-7 SMMR and DMSP SSM/I, http://nsidc.org/data/docs/daac/nsidc0079_bootstrap seaice.gd.html, for Natl. Snow and Ice Data Cent., Boulder, $\bar{C}$ Colo., June to Sept. 2001.

Connolley, W. M., A. B. Keen, and A. J. McLaren (2006), Results from the implementation of the Elastic Viscous Plastic sea ice rheology in HadCM3, Ocean Sci., 2, 201-211.

Curry, J. A., and P. J. Webster (1999), Thermodynamics of Atmospheres and Oceans, 465 pp., Academic, New York.

Ebert, E. E., and J. A. Curry (1993), An intermediate one-dimensional thermodynamic sea ice model for investigating ice-atmosphere interactions, J. Geophys. Res., 98(C6), 10,085-10,109.

Gordon, C., C. Cooper, C. A. Senior, H. Banks, J. M. Gregory, T. C. Johns, J. F. B. Mitchell, and R. A. Wood (2000), The simulation of SST, sea ice extents and ocean heat transports in a version of the Hadley Centre coupled model without flux adjustments, Clim. Dyn., 16, 147-168.

Hunke, E. C., and J. K. Dukowicz (1997), An Elastic-Viscous-Plastic model for sea ice dynamics, J. Phys. Oceanogr., 27(9), 1849-1867.

Ivchenko, V. O., V. B. Zalesny, M. R. Drinkwater, and J. Schröter (2006), A quick response of the equatorial ocean to Antarctic sea ice/salinity anomalies, J. Geophys. Res., 111, C10018, doi:10.1029/2005JC003061.

Iwi, A. M., R. T. Sutton, and W. A. Norton (2006), Influence of May Atlantic Ocean initial conditions on the subsequent North Atlantic winter climate, Q. J. R. Meteorol. Soc., 132, 2977-2999.

Johns, T. C., et al. (2006), The new Hadley Centre Climate Model (HadGEM1): Evaluation of coupled simulations, J. Clim., 19(7), 1327-1353.

Meredith, M. P., and J. C. King (2005), Rapid climate change in the ocean west of the Antarctic Peninsula during the second half of the 20th century, Geophys. Res. Lett., 32, L19604, doi:10.1029/2005GL024042.

Parkinson, C. L., K. Y. Vinnikov, and D. J. Cavalieri (2006), Evaluation of the simulation of the annual cycle of Arctic and Antarctic sea ice coverages by 11 major global climate models, J. Geophys. Res., 111, C07012, doi:10.1029/2005JC003408.

Rosati, A., K. Miyakoda, and R. Gudgel (1997), The impact of ocean intial conditions on ENSO forecasting with a coupled model, Mon. Weather Rev., 125(5), 754-772.

Serreze, M. C., and J. A. Francis (2006), The Arctic amplification debate, Clim. Change, 76, 241-264. 
Slingo, J. M., E. Guilyardi, K. Hodges, B. J. Hoskins, P. M. Inness, D. M. Lawrence, R. B. Neale, T. M. Osborne, H. Spencer, and G.-Y. Yang (2003), How good is the Hadley Centre climate model? Research at CGAM on identifying and understanding model systematic errors: 1999-2002, Hadley Centre Tech. Notes 67, 61 pp., Hadley Cent., Exeter, U. K.

Stroeve, J. C., M. C. Serreze, F. Fetterer, T. Arbetter, W. Meier, J. Maslanik, and K. Knowles (2005), Tracking the Arctic's shrinking ice cover: Another extreme September minimum in 2004, Geophys. Res. Lett., 32, L04501, doi:10.1029/2004GL021810.

Turner, J., W. M. Connolley, D. Cresswell, and S. Harangozo (2001), The simulation of Antarctic sea ice in the Hadley Centre Climate Model (HadCM3), Ann. Glaciol., 33, 585-591.

Turner, J., W. M. Connolley, T. A. Lachlan-Cope, and G. J. Marshall (2006), The performance of the Hadley Centre Climate Model (HadCM3) in high southern latitudes, J. Climatol., 26, 91-112.

Vinnikov, K. Y., D. J. Cavalieri, and C. L. Parkinson (2006), A model assessment of satellite observed trends in polar sea ice extents, Geophys. Res. Lett., 33, L05704, doi:10.1029/2005GL025282.
Winton, M. (2006), Does the Arctic sea ice have a tipping point?, Geophys. Res. Lett., 33, L23504, doi:10.1029/2006GL028017.

Wu, X., I. Simmonds, and W. F. Budd (1996), Southern hemisphere climate system recovery from "instantaneous" sea-ice removal, Q. J. R. Meterol. Soc. $122,1501-1520$.

Zhang, S., C. A. Lin, and R. J. Greatbatch (1995), A decadal oscillation due to the coupling between an ocean circulation model and a thermodynamic sea-ice model, J. Mar. Res., 53(1), 79-106.

Zhang, X. D., and J. E. Walsh (2006), Toward a seasonally ice-covered Arctic Ocean: Scenarios from the IPCC AR4 model simulations, J. Clim. 19(9), 1730-1747.

D. Schröder, University of Trier, Department of Environmental Meteorology, Faculty of Geoscience, Behringstrasse 21, D-54286 Trier Germany.

W. M. Connolley, British Antarctic Survey, NERC, High Cross, Madingley Road, Cambridge CB3 0ET, UK. (wmc@bas.ac.uk) 